occur in older women, there is a marked increase in the incidence of cancer among those aged under 35, in whom most smears are actually done.

As has been stated by some experts, cervical screening may be assumed simply to be holding in check a much larger potential increase in the incidence of invasive cancer in this young age group, possibly due to increased sexual activity. Epidemiological good sense might suggest continuing to perform frequent smears in this group and at that same time increasing smear rates in older women rather than decreasing the smear rates in the young and increasing the rate in older women.

Perhaps the sentence which sums up the present position best is in the leading article on failures of the cervical screening programme by Dr Jocelyn Chamberlain (6 October, p 853): "The principal reason for choosing five year screening intervals is cost." Given that with all screening programmes there is a delicate balance between cost and effectiveness it is time we told our patients that it is purely on grounds of cost rather than of efficacy that the DHSS is recommending a five year rather than a three year interval.

For the cervical screening programme to be more effective the primary health care system has to organise itself to take the smears, and the time interval at which they are taken must be seen to be appropriate both by people implementing the service and by the women who are screened. Why therefore is a five year interval being publicly advised at the moment, when privately three years is being advocated?

Oxford OX1 2NA

ANN MCPHERSON

SiR,-The many letters (3 November, $p$ 1223) in response to your leading article and papers on this subject (6 October, p 853, 883, 891, $894)$ reflect the range of practices and concerns that have developed in the cervical cytology screening programme in Britain. As one who was on the central advisory committee on gynaecological cytology for a dozen years, where strong representation was made to establish and organise a pattern of control of our then developing resources, I can identify the causes of failure.

Firstly, some 15 years ago we were assured that instead of a comprehensive countrywide coverage by cancer registries, which some other national screening programmes have successfully used, we were to use the computerised age-sex registers being developed in family practitioner committees, which then cope with all preventive health measures. The tardiness of this development, even when family practitioner committees were made conterminous with area health authorities in 1974, was a basic fault, and only recently has some improvement occurred. The Exeter family practitioner service computer unit states that by the end of next year nearly half of the population should be recorded on family practitioner committee computers.

It has been characteristic of Britain's approach to such problems to allow a great degree of licence to individual health authorities, which has resulted in very patchy progress. Now as a result of a significant increase in the incidence of cervical cancer in the young there is a further danger of a multiplicity of computer systems being introduced. There call system of the family practitioner committee must dovetail into the system for repeat requests of the health authority laboratories. There is a further complication in the conurbations, where the number of attenders at clinics from other districts may be four or five times that of those from the local population. This again argues for uniformity of practice and computer systems.
Dr Carolyn D Ritchie and Miss Patricia Last (p 1224) mention the loss to follow up of many of their patients. We have ourselves run a manual laboratory repeat request system for over 20 years for a subregional service; one analysis showed that we were getting about $93 \%$ compliance from GPs and clinic doctors in controlling such cases through maintaining a simple diary list and sending follow up letters, on which we type the previous test report (an important factor in the reminder) and allowing space at the bottom of the form for a simple handwritten reply. Dedicated staff and a good rapport with GPs and clinic staff make such results possible.

The idea of a personal record card is another valuable adjunct. This idea was tried out 10 to 15 years ago by Dr MacIntyre of Leeds, who found that many were lost over the space of a few years. I believe with Dr M C D Heath that the method should be tried again as people are now more receptive to such forms of control and it would avoid unnecessary duplication of smears.

Perhaps we should recreate the coordinating committees that were developed early in the screening service. They brought together gynaecologists, cytopathologists, general practitioners, public health officers, and family practitioner representatives as well as the voluntary organisations to make sure that a comprehensive service was provided, creating effective cooperation and identifying target norms.

There is an urgent need for a central pronouncement on the best way to present a coordinated attack on a problem that, after many years and at much cost, we have failed to tackle as successfully as other countries.

Regional Cytology Centre, St Stephen's Hospital,

O A N Husain

SIR,-The leading article by Dr Jocelyn Chamberlain, the report from the Imperial Cancer Research Fund Coordinating Committee on Cervical Screening, and the article by Professor J M Ellwood and others highlight the deficiencies of the British cytology screening service. The time has come for a complete rethink. Too many unnecessary smears are taken.

In countries such as those in Scandinavia, where screening is systematic and based on population registers, there has been a fall in the incidence of and mortality from cervical cancer. The ICRFCC paper proposes a system based on family practitioner committee lists and Dr Philips (3 November) describes this even more succinctly.

Family practitioner committee (primary care in Scotland) computers are designed to keep names of patients registered with individual GPs so that the doctors may be remunerated correctly. Ninety eight per cent of women are registered with general practitioners, so for the first time all women can be identified. Screening at regular intervals based on call and recall from these names need be the only source of smears. The women would be notified and given an appointment. Payment should be made for these routine smears from women of all ages. Most GPs now have ancillary staff, who can help them ensure the attendance of the most vulnerable the sexually active women. A copy of the normal smear reports could go directly to the family practitioner committee so that GPs could be saved considerable form filling.

Smears need no longer be taken at family planning or antenatal or postnatal clinics.
Incidental smears taken by gynaecologists because of symptoms would not be regarded as screening smears. A recall system for all patients with abnormal smears should clearly be the responsibility of the reporting laboratory, which could use the family practitioner committee facilities for tracing patients. The laboratory files could be manual (Dr C Pike, 3 November, p 1224) or on a microcomputer. The interval between smears should be decided in line with current research.

J Elizabeth MaCgregor Department of Pathology, University of Aberdeen

SIR,-Having recently discussed the articles on cervical screening at our journal club, we feel the problems are the same as those summarised at the end of the British Society for Clinical Cytology pamphlet of 1981: "Women who are now dying from cervical cancer are those who have never had a smear." As the main obstacle seems to be in offering access to the screening programme to those who may never have even contemplated such an investigation, would it not be appropriate to encourage the drug companies and firms making associated products, such as oral contraceptives and tampons, to carry a health advisory note to try to bridge this gap-for example, "It is every woman's right to have a cervical smear-they save lives. Have you had one in the past five years ?" We feel that such a notice could only improve the current situation of needless deaths in an unscreened population.

JOHN OSBORNE KEITH EDMONDS FRANK LOEFFLER

Queen Charlotte's Maternity Hospital,
London W6 OXG

\section{Colposcopy in a district general hospital}

SIR,-Without wishing to detract from the article by Dr Albert Singer and his colleagues (20 October, p 1049), I must say that their concluding section on costs is weak and misleading. They state, "Once the capital outlay for equipment has been made there are substantial savings for the district general hospital in the introduction of a colposcopy clinic." The substantial savings appear to refer to the average costs of traditional inpatient treatment - that is, cone biopsy under general anaesthesia. Because average cost includes overheads it is not a realisable financial saving. Whether or not such patients are admitted, staff salaries must be paid and wards heated, lit, and cleaned. Thus the only real saving is the marginal cost of treating such women as inpatients - that is, the additional cost of stationery, food, drugs, etc, associated with such admissions. Of course, if the reduction in the inpatient load is large enough to allow, say, a ward to be closed then a substantial saving will be realisable. This is unlikely to occur in practice as such "empty" beds would tend to be used to admit patients on waiting lists for elective surgery.

I agree with Dr Singer and his colleagues that a colposcopic service should be widely available to all women with abnormal cervical smears. It would appear to be much more socially efficient than traditional inpatient treatment, but the associated "substantial 
financial saving" that they refer to is not nearly as large as they suggest.

\section{J Hospedales}

Norwich Health Authority,

Norwich HR1 1LS

SIR,-Your readers might like to know what impact this clinic made on the general practitioners and their patients in the area. When the service started we received a short card stating briefly that "there is now a colposcopy department at the Royal Northern Hospital to deal with abnormal smears." Shortly afterwards general practitioners began to receive much modified cervical cytology reports referring to "dysplasia," "koilocytosis," "dyskeratosis," and some containing the added suggestion "Colposcopy referral recommended." We were besieged by anxious patients who wanted to know what the "dysplasia" was and what to expect at the clinic. It was a most harrowing experience for any woman to be told that an abnormality had been found on the cervix which would need colposcopic assessment, and that her appointment was to be in six weeks' time. Quite soon some of our patients were destined for "laser ablative therapy," and again had to wait several weeks.

As time went by letters from the hospital began to acquire some meaning, there was a lecture by the consultant, and GPs began to comprehend the ease with which cervical pathology could be assessed and the treatment tailored to the patient's needs. Many of our patients had their carcinomas in situ evaporated by the laser in less than 10 minutes, as outpatients and without general anaesthesia, with a cure rate of $95 \%$. This was most welcome and we are very grateful for the clinic. We hope there will be many more throughout the country, but please remember when setting up a clinic to devise an informative letter about the clinic for the referring doctors and their patients.

\section{London $\mathrm{N} 8 \mathrm{8HJ}$}

JANE Chomet

\section{Colposcopy and ablative therapy}

SIR,-I was disappointed with the discussion on local ablative therapy in the leading article by $\mathrm{Dr} J$ Elizabeth Macgregor (20 October, $p$ 1024). Although she emphasised the importance of long term follow up as the only way to justify local ablative therapy, many of the references included only short term follow up of patients. The outstanding exception, unfortunately omitted, is Chanen's series from Melbourne, in which he used electrodiathermy after colposcopy, on a day case basis. Results have been published of a 15 year follow up (1966-81), with a $97 \cdot 3 \%$ cure rate. ${ }^{1}$ This method is safe and proved to be effective by the length of the follow up. Laser therapy has yet to achieve these results, and a word of caution is necessary amid the euphoria of your leading article. At Barnet General Hospital we have followed the Chanen regimen since 1976 without cause for regret, but our follow up is relatively short (eight years).

Incidentally, no one has to wait for more than one week to be seen in the colposcopy clinic. One of the reasons for this is that treatment is not carried out in the clinicjust diagnosis-and arrangements are made thereafter for day case diathermy destruction when the results of repeat smears and biopsies are available.

\section{Barnet General Hospital
Barnet, Herts EN5 3DJ}

HARveY WAGMAN

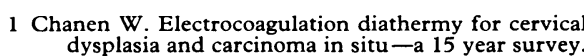
dysplasia and carcinoma in situ
Obstet Gynecol 1983;61:673-9.

\section{“Are you doing your job ?”}

SIR,-As a general practitioner in a district of London where there are people of many races, I assume that the advertisement on the second page of last week's $B M F$ ( 10 November, clinical research edition) is aimed at me. Comments from my colleagues in the past few days tel me that I am not alone in finding it dishones and offensive.

"All the evidence shows that ethnic minorities are regularly denied access to treatment by the health service." Does it? Are immigrants being turned away by hospitals and general practitioners? To what evidence does the advertisement refer? I know of none, but it is relevant that a recent and thorough study of the question of access to doctors in London showed that of the few people who had problems in finding a doctor, coloured people actually fared better that whites in this respect. $^{1}$

"If you take no account of your patient's [sic] religious customs or diets, how can you treat them effectively ?" asks the anonymous advertiser. The answer is that you cannot but who does not take account of them so? The advertisement contains several questions like this, all implying that doctors in London treat immigrants badly. This is grossly unfair to the doctors in hospital and in the community who are working hard to deal with the complex problems-medical and social-of patients from abroad. Being on the district managemen team for Tower Hamlets and the family practitioner committee for East London, I know of the great amount of time and effort devoted to catering for the special needs of these patients. Apart from hundreds of daily consultations, we have notices, leaflets, audiotapes, and videotapes in various languages, special antenatal classes, and so on.

We doctors, nurses, and administrators in London do not expect praise for our work but we do ask that we should not be offered a gratuitous insult by a whole page of the $B M F$. (Incidentally, this is the only advertisement in the journal which does not give the name or address of those responsible for it.)

\section{JAMES N DOCHERTY}

London E1 1 Bone M. Registration with general medical practitioners
in inner London. London: HMSO, 1984.

** The advertisement was placed by the Greater London Council as part of its antiracism campaign.-ED, $B M \mathcal{F}$.

\section{AIDS: an old disease from Africa?}

SIR,-I would like to reply to some of the thoughtful points raised by Dr R Colebunder and others (22 September, $p$ 765) in response to my article (4 August, p 306). No certainty exists about the origin of the acquired immune deficiency syndrome (AIDS). The causative agent, however, must have come from some- where, and the discovery of its origin would greatly increase our understanding of the syndrome. That AIDS is an African disease is a more plausible hypothesis than any other that has been proposed. The Belgian workers must see at least some merit in it, or they would not be carrying out such extensive research on AIDS in central Africa.

It is true that only a few cases of possible AIDS in Africans were reported before the current Western epidemic. ${ }^{12}$ This is inevitable, since the syndrome has only recently been defined, and retrospective diagnosis is fraught with difficulty. Nevertheless, these early African cases of opportunistic infections in previously healthy people sound very much like real cases of AIDS. Such cases would not have gone unreported in the West. Without well documented cases elsewhere, it is difficult to see how AIDS could have been introduced into central Africa from outside.

Sporadic cases of obscure infections such as central nervous system cryptococcosis have certainly occurred world wide. There is a great difference, however, between occasional and isolated cases of unusual infections and the current epidemic of AIDS. To suggest that isolated instances of cryptococcosis might have been cases of AIDS is speculative. Again, the question arises: where would such infections with the AIDS agent have come from? Apart from their geographical links with the current African outbreak, the early African cases were also characterised by multiple opportunistic infections rather than individual ones. ${ }^{12}$

Dr Colebunders and his colleagues comment that AIDS in Rwanda has been recognised most often in an urban environment. ${ }^{3}$ Sexual promiscuity and prostitution seem risk factors. These observations do not exclude a rural origin for the disease. Hospitals in developing countries are often concentrated in urban centres, and epidemiological conclusions drawn from hospital records can be notoriously misleading. It is easy to see how promiscuity and prostitution could amplify the spread of a sexually transmitted disease like AIDS within a city population. The epidemics of AIDS in $\mathrm{Kinshasa}^{4}$ and $\mathrm{Kigali}^{3}$ may be new phenomena, but that simply suggests that the AIDS agent has only recently entered these cities. Yellow fever offers an example of a condition with a rural origin which can produce epidemics in urban populations.

Too much may have been made of the fact that most Western patients with AIDS are homosexuals. A virus is unlikely to infect selectively on the basis of race, nationality, or sexual preference. The risk factors for AIDS are not being homosexual, African, or Haitian; they are having sexual intercourse with, or being exposed to blood from, another individual infected with the AIDS agent. A high carrier rate of hepatitis $B$ virus infection among male homosexuals is the result of sexual promiscuity within an enclosed ecosystem, as well as male predisposition to becoming a carrier. It does not result simply from homosexuality. Your correspondents' suggestion that homosexuals may have introduced AIDS into Africa seems improbable. Homosexuality has existed throughout history, but the AIDS epidemic is new. It is more likely that the AIDS agent has recently gained entry into the homosexual community, and that homosexual practices have since then amplified its spread.

The Belgian workers comment that classical Kaposi's sarcoma is clinically, immunologically, and epidemiologically different from the more aggressive variety seen in AIDS. With their extensive African contacts they have experience and information not generally available, but I am aware of only one published report on the relation (if any) between classical Kaposi's sarcoma and AIDS. ${ }^{5}$ Reports from Zambia suggest that aggressive Kaposi's sarcoma is being seen more often, ${ }^{6}$ and that Zambian patients with the tumour have reversed ratios of $T$ helper to $T$ suppressor cells. ${ }^{5}$ Some patients, especially children, have always had the aggressive variety of Kaposi's sarcoma, ${ }^{7}$ and immunological abnormalities have been noted in such cases. ${ }^{8} 9$ Studies to establish the relevance of classical Kaposi's sarcoma to AIDS should have a 